\title{
Analysis of extraction level layouts for block caving
}

\author{
RE Gómez University of Concepción, Chile \\ K Saéz University of Concepción, Chile \\ N Pino University of Concepción, Chile \\ E Labbe CODELCO, Chile \\ E Marambio AMTC, University of Chile, Chile
}

\begin{abstract}
Designs for extraction level layouts used in block caving mines may vary in terms of geometrical configuration and dimensions. The design of the extraction level in caving mines is mainly based on maximizing ore recovery at a low cost under safe and stable conditions. In this paper, we analysed the extraction level layouts commonly used as well as variations proposed with a specific focus on stability and productivity. The El Teniente layout was used as a base case with dimensions of $15 \times 17.32 \mathrm{~m}^{2}$, production and extraction drifts of $4.3 \times 3.6 \mathrm{~m}^{2}$, LHD of $7 \mathrm{yd}^{3}$ and a productivity of 3,000 tpd per production drift. This base case was compared with three layouts: the Herringbone layout, a modified, enlarged El Teniente layout, and a modified, enlarged Square layout. Productivity was analysed through stochastic simulations using the software Arena; stability analysis used Examine3D software. Results indicated that in the new proposed layouts-the modified El Teniente layout and the modified Square layout-productivity increased by $33 \%$ and $39 \%$, respectively, whereas the cycle time decreased by $23 \%$ and $25 \%$ with regards to the base case. In terms of stability, the Herringbone layout had the best safety conditions on the walls of the production and extraction drifts, whereas the modified, enlarged El Teniente layout had the best safety conditions on the roofs of the production drift. Finally, it is concluded that the modified layouts can contribute to increasing ore recovery while decreasing the cyle time without sacrificing stability.
\end{abstract}

\section{Introduction}

In block caving mines, the extraction level layout is designed mainly to maximize ore extraction and mine stability. Ore is drawn from drawpoints using load-haul-dump (LHD) equipment, which moves through drifts with different sizes and distributions. The main drifts are commonly known as production drifts and extraction drifts, and the locations of these drifts are specified in the extraction level layout.

The most typical extraction level layouts are the El Teniente layout and the Herringbone layout (Chacón et al. 2004; Chitombo 2010). The El Teniente layout uses a triangular configuration of extraction ellipsoids, whereas the Herringbone layout uses a mixed configuration of extraction ellipsoids. Both layouts have advantages and constraints in terms of equipment movement, stability, operational safety, and development (Chacón 1976; Laubscher 2000). As an example, in the El Teniete layout, the LHD can only load ore from the extraction drifts located at its right. In the Herringbone layout, the LHD can only load ore in one direction of movement. Both layouts are shown in Figure 1. 


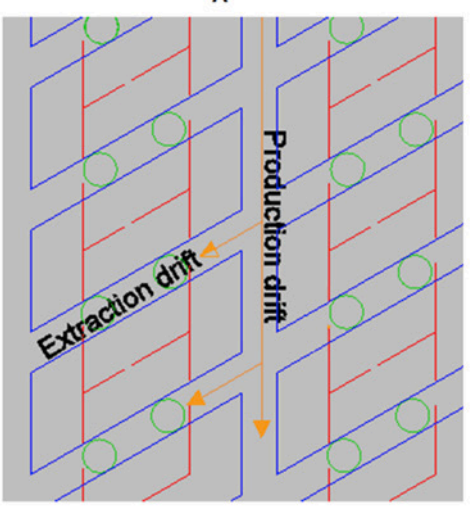

B

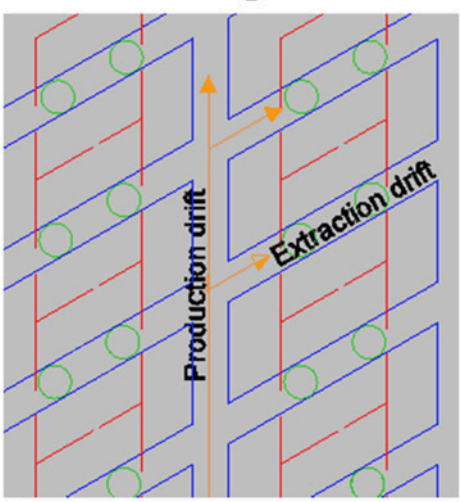

C

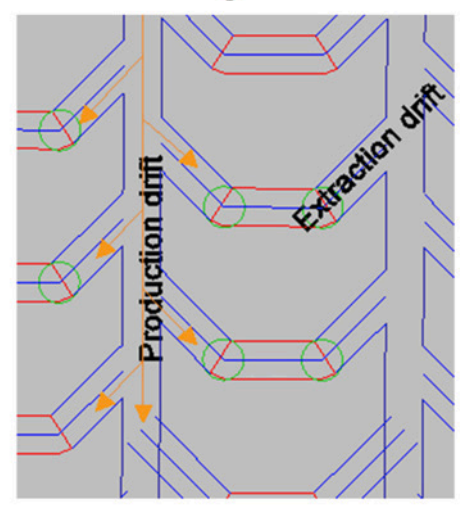

Figure 1 LHD's direction of movement indicated with yellow arrows in the extraction level layouts, plan view. A: El Teniente layout, B: Herringbone layout

The El Teniete layout was initially implemented in 1982 at El Teniente mine in response to secondary ore depletion and LHD implementation (Jofre et al. 2000). The Herringbone layout was developed at Henderson mine using a mixed configuration of extraction points (Rech 2001). The Square layout was used at El Teniente mine, specifically at Ten-5 Pilares and Quebrada Teniente sectors (Arce 2002). In Ten-5 Pilares, this layout was implemented by scraper system and in Quebrada Teniente using manual extraction. The Square layout is not typically used with LHDs in block caving mines because of operational problems as demonstrated in an engineering study for panel caving (Wellmann 2001). Nonetheless, it was included in this study because if the turning radius of the LHD could be accommodated through modifications, this layout might present an alternative for planning usage.

A summary of several extraction level layouts are shown in Table 1. (Chacón 1976; Aimin \& Yongxue 2000; Rech 2001; Aguayo et al. 2004; Bull et al. 2004; Chacón et al. 2004; Flores et al. 2004; Hannweg 2004; Hersant 2004; Yuming \& Jinfeng 2008; Ross 2008; Catalan et al. 2012; Capes et al. 2012).

Table 1 Summary of various block-caving layouts used. * More than one spacing can exist

\begin{tabular}{|c|c|c|c|c|c|}
\hline Mine & Country & Layout & Spacing* & $\begin{array}{c}\text { Production drift, } \\
\mathbf{m}^{2}\end{array}$ & Depth, $\mathbf{m}$ \\
\hline Andina & Chile & El Teniente & $\begin{array}{c}13 \times 13 \text { and } \\
13 \times 15\end{array}$ & $4 \times 3.6$ & 3236 masl \\
\hline Argyle & Australia & Herringbone & $15 \times 16$ & - & $\sim 1,000$ \\
\hline Cadia East & Australia & El Teniente & $16 \times 20$ & - & 1,475 \\
\hline El Teniente & Chile & El Teniente & $15 \times 15$ & $4.3 \times 3.6$ & 1800 masl \\
\hline Finsch & South Africa & $\begin{array}{c}\text { El Teniente / } \\
\text { Herringbone }\end{array}$ & $15 \times 15$ & $4.6 \times 4.8$ & 830 \\
\hline Freeport-DOZ & Indonesia & $\begin{array}{c}\text { El Teniente / } \\
\text { Herringbone }\end{array}$ & $15 \times 17.3$ & $4 \times 3$ & 3120 masl \\
\hline Henderson & United states & Herringbone & $15.25 \times 17.1$ & $4.3 \times 4.3$ & 3170 masl \\
\hline Koffiefontein & South Africa & Herringbone & & $4 \times 4.2$ & 720 \\
\hline Northpakes & Australia & Herringbone & $18 \times 15$ & - & - \\
\hline Palabora & South Africa & Herringbone & $17 \times 17$ & $4 \times 4$ & 1,200 \\
\hline Premier Diamond & South Africa & Herringbone & $15 \times 15$ and & $3.6 \times 3.8$ and & $630-732$ \\
\hline Ridgeway Deeps & Australia & Herringbone & $15 \times 18$ & $4.2 \times 4.2$ & \\
\hline Salvador & Chile & Herringbone & $12 \times 12.5$ & $4.3 \times 3.8$ & 4786 masl \\
\hline Tongkuangyu & China & Herringbone & $15 \times 15$ & $4.2 \times 3.4$ & 690 masl \\
\hline
\end{tabular}


Table 1 shows that the El Teniente and Herringbone layouts are commonly used. Also, different spacing and drift areas are used. In this paper we compared four layout configurations, including the two most commonly used, to investigate if productivity could be increased while maintaining the stability of the mine design.

\section{Methodology}

This section describes the methodologies used to evaluate four production level layouts that can be used in block caving. The base case considered to define the input parameters is a Chilean copper mine, where the El Teniente layout is used, with production drifts oriented N15' W of $4.2 \times 3.9 \mathrm{~m}^{2}$ spaced 30 $\times 17.3 \mathrm{~m}^{2}$. Extraction drifts are located $60^{\circ}$ from production drifts. This configuration defines an area of $259.5 \mathrm{~m}^{2}$ per drawpoint.

The rock mass formed mainly by primary ore is massive competent, with a high-frequency network of small-scale veins (Brzovic \& Villaescusa 2007). The Rock Mass Rating is between of $52-65$, the Q index between 4.3 - 5.5 and the Geological Strength Index between of 70-90 (Hurtado et al. 2007).

\subsection{Production level layouts}

Four layouts were analyzed in this study. The commonly used El Teniente and Herringbone layouts, as well as two new proposed layouts: the modified El Teniente layout and the modified Square layout. These two proposed layouts add more flexibility for maneuvering the LHD equipment.

In the El Teniente and the Herringbone layouts, the LHD direction and movement suffer certain operational restrictions as shown in Figure 1. A modification involving pillar excavation was proposed to avoid these constraints. For The El Teniente layout, the modification involved changing the geometry based on the turning radius of the LHD used in the base case $(\mathrm{CAT}$ R1600H) by removing a section of each production pillar as shown Figure 2A. This modification effectively enlarged the space available for the LHD so as to eliminate the typical limitations of the standard layout.

An enlargement modification was also applied to the square layout as shown in Figure 2B.
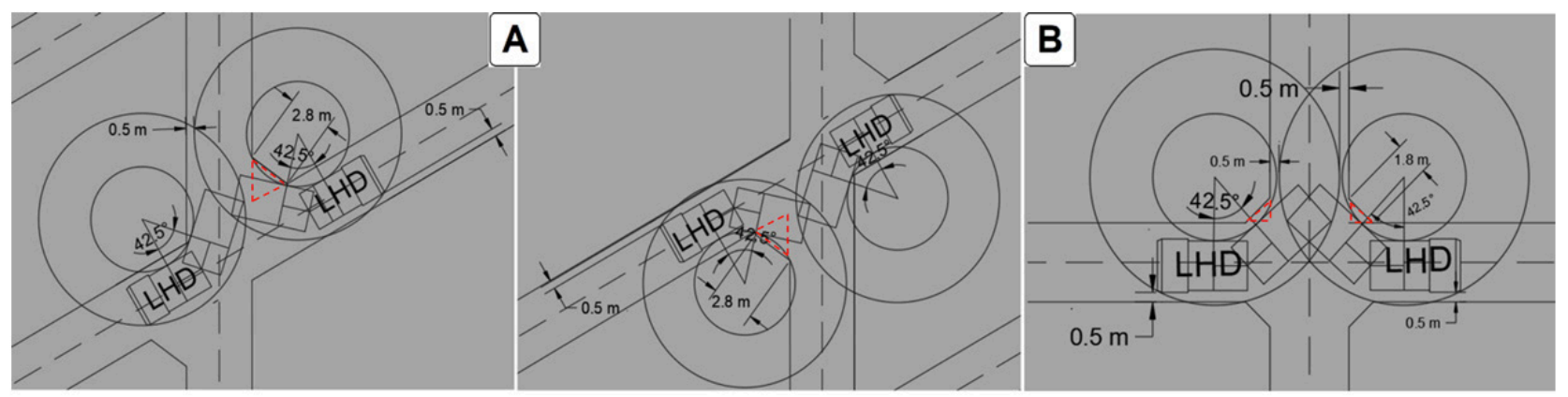

Figure 2 Modified pillars (red triangles) based on turning radius, Plan View. A: The modified El Teniente layout. B: The modified Square layout

The four layouts defined in this study with their geometries and enlargements are presented in Figure 3. In Figure 3B and 3C, the enlargement added allows the LHD to enter a drawpoint in any direction of movement. 


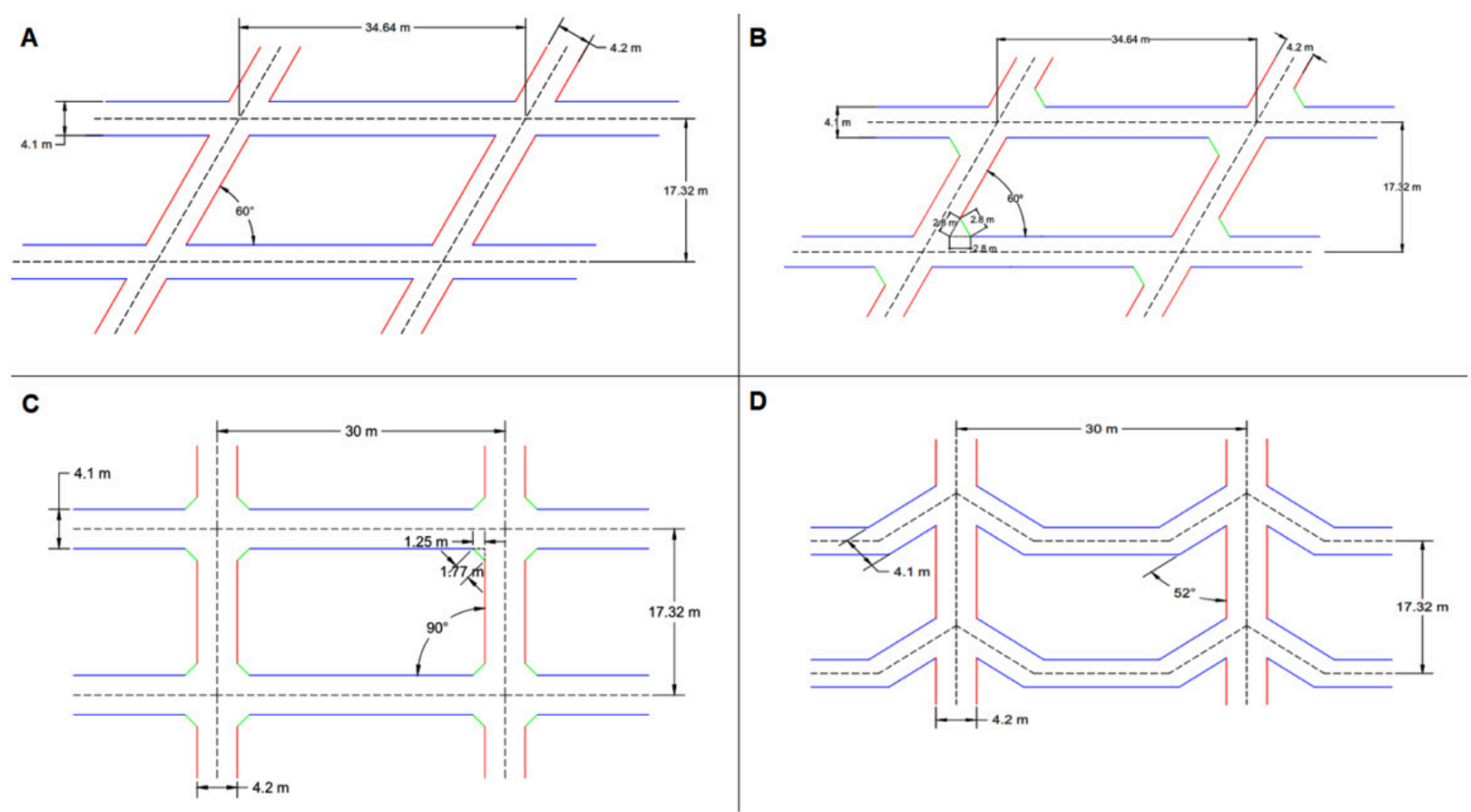

Figure 3 Layouts analyzed in this work, plan view. A: El Teniente layout, B: El Teniente Modified-Enlarged layout, C: Square Modified-Enlarged layout, D: Herringbone layout

\subsection{Stability considerations}

The stress behavior around the excavation was used to analyses the layout stabilities. A base case from the El Teniente layout was selected to define the input parameters of geometries, rock type and stress field. The stress distributions were compared between layouts in the walls and roofs of the production drift, in the extraction drift, and in the zones that were modified by enlargement.

Examine3D software, based on the boundary element method, was used in this stage. The numerical model was built with a mesh formed by triangulated nodes that gives the model its volume. An analysis of the rock deformation characteristics was developed considering the rock mass elastic behavior, taking into account that this analysis may not fully represent the real convergence of the rock mass. However, this tool does provide a good approach to analyze stress.

The base case was a sector of a Chilean Block Caving mine that used the El Teniente layout with an Esmeralda- type drawbell. The following considerations were used: The numerical model uses the average values of parameters required (obtained from literature references here); A continuous surface of the excavation is used in a homogenous media; Excavation are assumed to be voids; The presence of water or joints in the rock mass is outside the scope of this study; Stresses related to broken material in the drawbells are not included in the analysis; The four layouts are $15 \mathrm{~m} \times 17.32 \mathrm{~m}$ and the production and extraction drift dimensions are shown in Figure 4. 


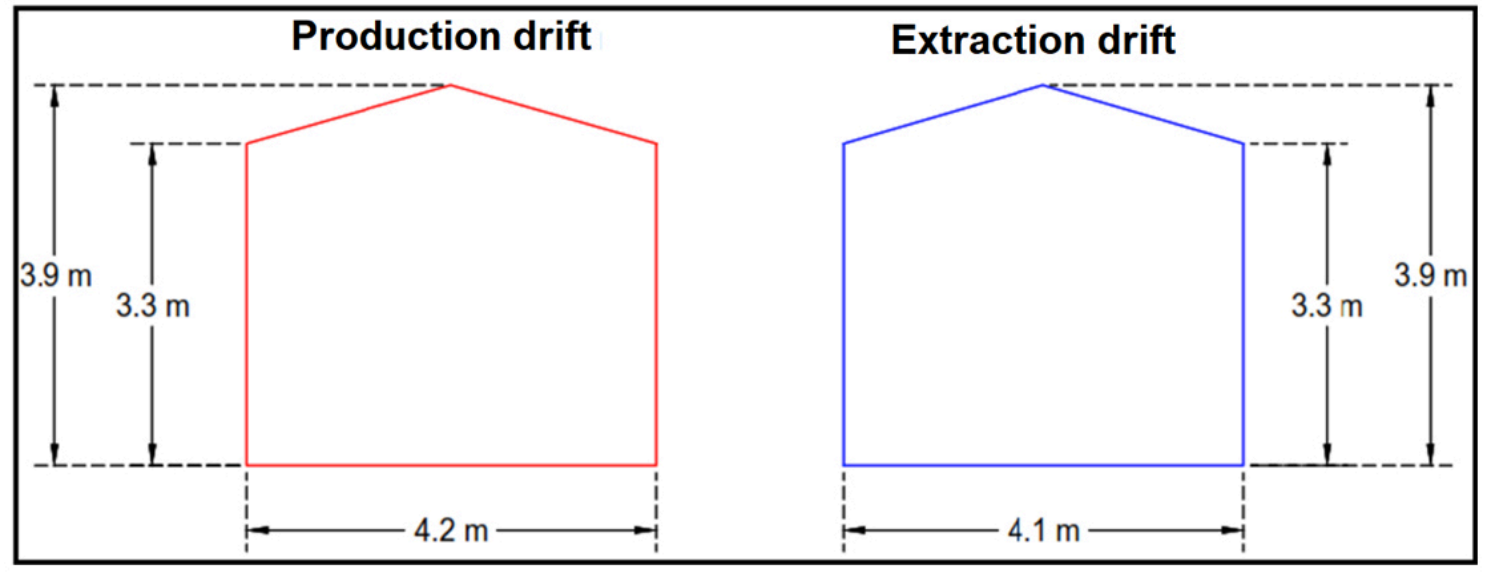

Figure 4 Drift dimensions: profile view

Layout nomenclature: El Teniente Layout (TL); Modified El Teniente Layout (MTL); Modified Square Layout (MSL); Herringbone Layout (HL).

The geotechnical information of the base case required for the numerical model is shown in Table 2. The parameters " $\mathrm{m}$ " and " $\mathrm{s}$ " of the Hoek-Brown failure criteria, the elastic constant (E and $\mathrm{v}$ ), the stress field and rock strength $\left(\sigma_{c i}\right)$ are indicated.

Table 2 Geotechnical parameters used in the model (Codelco 2016; Sepúlveda 2017)

\begin{tabular}{|c|c|c|c|c|}
\hline Parameter & Unit & Value & DipDir & Dip \\
\hline$E$ & $\mathrm{GPa}$ & 55 & - & - \\
\hline$v$ & - & 0.25 & - & - \\
\hline$\sigma 1$ & $\mathrm{MPa}$ & 63 & $165^{\circ}$ & $0^{\circ}$ \\
\hline$\sigma 2$ & $\mathrm{MPa}$ & 40 & $75^{\circ}$ & $0^{\circ}$ \\
\hline$\sigma 3$ & $\mathrm{MPa}$ & 21 & $0^{\circ}$ & $90^{\circ}$ \\
\hline$\sigma c i$ & $\mathrm{MPa}$ & 132 & - & - \\
\hline$m$ & - & 4.954 & - & - \\
\hline$s$ & - & 0.062 & - & - \\
\hline
\end{tabular}

The stress measurements were carried out on the production drift, extraction drift and on a modified pillar (between production and extraction drifts) in each layout with query points in the walls and roofs.

\subsection{Stochastic simulation}

Following analysis of stability, an analysis of productivity was carried out in the four layouts. In this stage, the productivity related to one production drift (one LHD) was simulated. Here, the productivity of the base case (El Teniente layout) is known and was used to calibrate the simulation model of the base case. Then, the simulation models for the other layuouts (Modified El Teniente, Modified Square and Herringbone) were built. The simulation models were developed in Arena software.

The model considered the following parameters: effective working hours per shift, LHD maneuvers, hang-up events in drawpoints (DPs), and LHD dumps on an ore pass. In an effort to focus on productivity, operational interferences were not included in the simulation.

\subsubsection{Main elements and considerations}

The main elements of the simulation were locations, resources involved, and activities. Locations included those that affect the LHD productivity such as the ore pass, drifts, and drawpoints. The resources are the 
LHD, while the activities are the loading, transporting, ore dumping, emptying transport and maneuvering the LHD. The simulation parameters used and further conditions included the following:

- A production drift is simulated for one month using one LHD, 15 extraction drifts, and two ore passes. The distances from drawpoint to closest ore pass have the following distribution: Average distance is $83.6 \mathrm{~m}(\mathrm{TL}, \mathrm{MTL}, \mathrm{MSL})$ and $88.3 \mathrm{~m}(\mathrm{HL})$, minimum distance is $9.4 \mathrm{~m}(\mathrm{TL}, \mathrm{MTL}, \mathrm{MSL})$ and $13.2 \mathrm{~m} \mathrm{(HL)}$, and the maximum distance is $182.6 \mathrm{~m}(\mathrm{TL}, \mathrm{MTL}, \mathrm{MSL})$ and $186.4 \mathrm{~m}(\mathrm{HL})$.

- The base case productivity is 3,000 tpd. LHD model CAT R1600H used was $7 \mathrm{yd}^{3}$, with a bucket capacity that follows a triangular probability distribution: lower limit of 7.77 [t], upper limit of $11.77[\mathrm{t}]$ and mode of $9.77[\mathrm{t}]$.

- The LHD loading time is a triangular probability distribution: lower limit of 0.33 [min], upper limit of 0.58 [min] and mode of 0.83 (min).

- The LHD dumping time is a triangular probability distribution: lower limit of 0.25 [min], upper limit of 0.58 [min] and mode of 0.33 [min].

- The average LHD velocity is $2.0[\mathrm{~m} / \mathrm{s}]$ empty and $3.0[\mathrm{~m} / \mathrm{s}]$ full.

- The LHD maneuver time and turning time of [min], depended on the layout simulated.

- A hang-up event in a drawpoint occurs with every 1,000 ton drawn (Hang-up index of 1 [hangup/1000 t]).

- If there are 12 drawpoints with hangups, a secondary reduction activity is developed to release the hangup. The secondary reduction time follows a triangular probability distribution: lower limit of 3.2 [h], upper limit of $4.8[\mathrm{~h}]$ and mode of 4.0 [h].

- Operational interference is not included in the simulations in the ore passes.

In this stage, four production drifts (one per layout presented in section 2.1) were simulated. Additionally, two scenarios were applied per layout. In scenario 1, the LHD have the same probability of going to drawpoints. In scenario 2, the LHD have different probabilities of going to drawpoints, depending on the distance between the drawpoint and the ore pass. Scenario 2 attempts to replicate poor operational practice that can be observed in some block caving operations to increase shift productivity.

\subsubsection{Simulation model}

Figure 5 shows the conceptual model used in the LHD simulation.

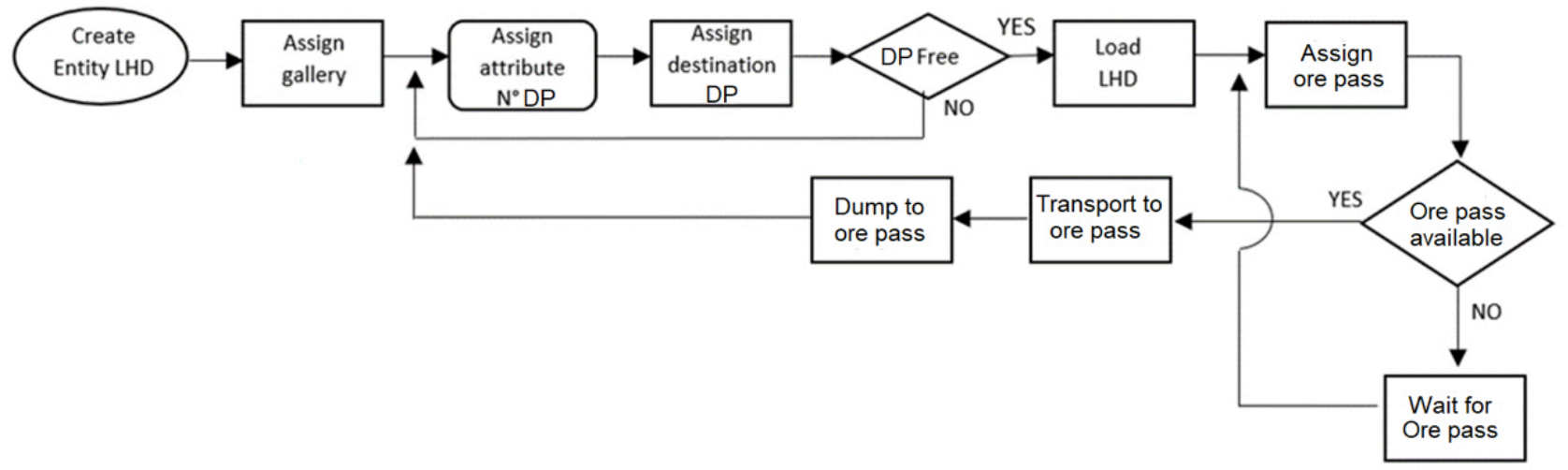

Figure 5 Conceptual model used in Arena to simulate the LHD productivity

The El Teniente layout was the base case used to calibrate the simulation model. The distance travelled by the LHD depends on the layout and the drawpoint locations. Then, the cycle time is the result of these distances and the time required in the different activities defined in section 2.3.1. Here the LHD velocity is $7.2 \mathrm{~km} / \mathrm{h}$ empty and $10.8 \mathrm{~km} / \mathrm{h}$ full. The productivity is determined by the cycle time and LHD capacity. 


\section{$3 \quad$ Stability Results}

This section presents the stress results $(\sigma 1, \sigma 3)$ and the Strength Factor (SF) of the layouts simulated in Examine 3D. The SF is defined as following,

$$
S F=\frac{S_{\max }}{S}
$$

Where, Smax is the rock maximum strength under compression, and $\mathrm{S}$ is the total Stress. These parameters are determined in Examine3D (Rocscience 1994), using the Hoek and Brown Failure criterion as,

$$
S_{\text {max }}=\frac{\sqrt{\left(1-\frac{\tan (\phi)}{\sqrt{3}}\right)^{2}\left(\frac{m \sigma_{c}}{8}\right)^{2}+\left(\frac{m \sigma_{c} I_{c}}{12}+\frac{s \sigma_{c}^{2}}{4}\right)-\frac{m \sigma_{c}}{8}\left(1-\frac{\tan (\phi)}{\sqrt{3}}\right)}}{\cos (\phi)}
$$

Where, $\phi$ is the internal friction angle, $\sigma_{\mathrm{c}}$ the uniaxial compression strength, $I_{c}$ is $\left(\sigma_{\mathrm{x}}+\sigma_{\mathrm{y}}+\sigma_{\mathrm{z}}\right)$ and $\mathrm{m}$ is a Hoek-Brown parameter. And,

$$
S=\sqrt{J_{2}}=\sqrt{\frac{1}{6}\left(\left(\sigma_{x}-\sigma_{y}\right)^{2}+\left(\sigma_{y}-\sigma_{z}\right)^{2}+\left(\sigma_{z}-\sigma_{x}\right)^{2}\right)+\tau_{x y}^{2}+\tau_{y z}^{2}+\tau_{z x}^{2}}
$$

Where, $\sigma_{i}$ is the normal stress in the $i$ direction, and $\tau_{i j}$ is the shear stress orthogonal to $i$ in the $j$ direction. The stresses are induced by layouyt geometries tested ( $T L, M T L, M S L, H L)$. The undercutting is not considered. The model used to analyze layout geometries is $138 \mathrm{~m} \times 69 \mathrm{~m}$. Excavation boundaries are not included.

\subsection{Strength factor}

\subsubsection{Walls}

The query points in the walls were spaced $50 \mathrm{~cm}$ starting from the floor to the roof $(3.3 \mathrm{~m})$. Figure 6 shows the results for the three zones of interest: Production drift, extraction drift and modified enlargement zone). A green line indicated in the bottom right of graphs shows the query-point locations in the drift in a profile view.

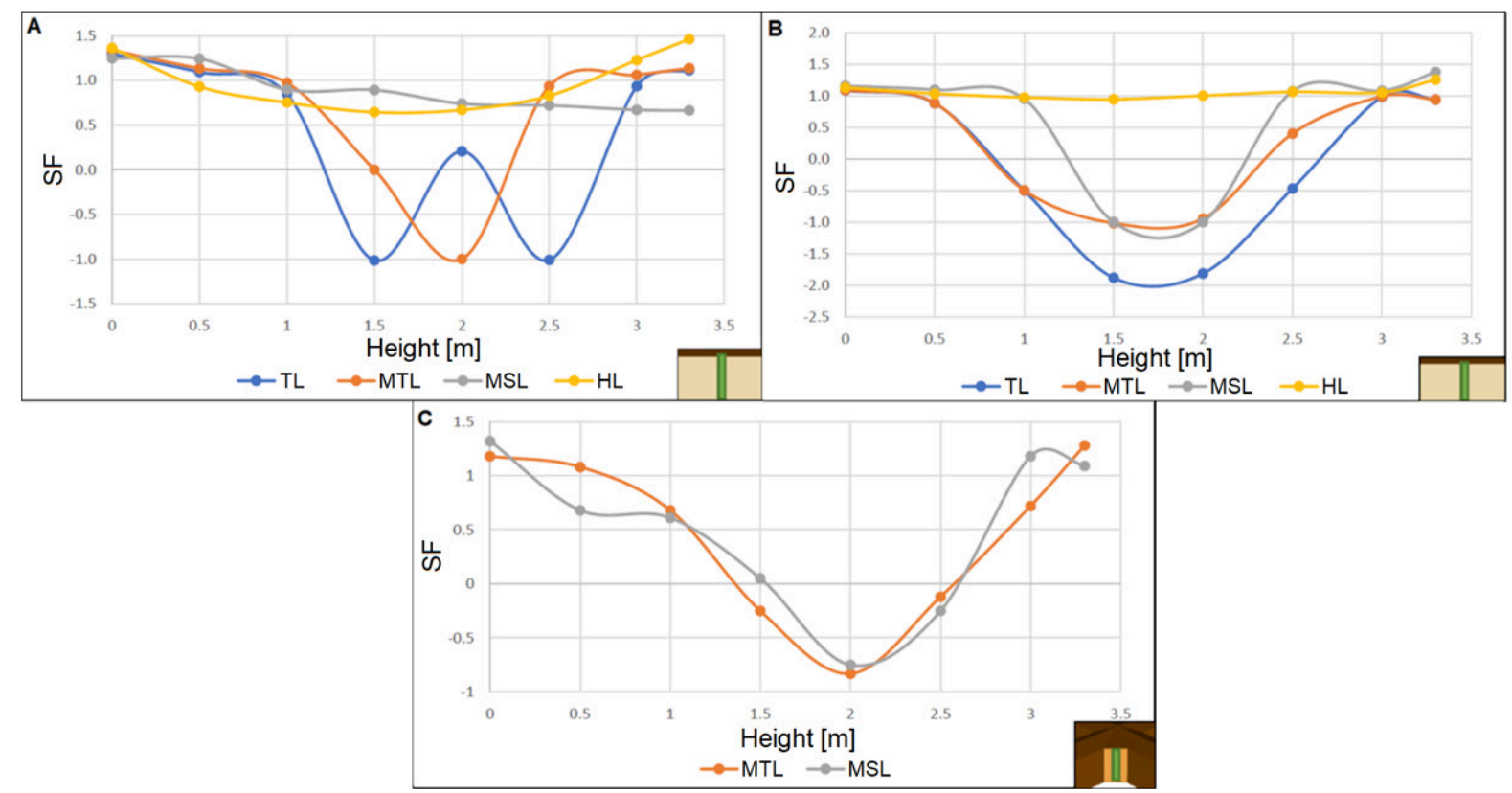

Figure 6 Strength factor results on drift walls, A: Production drift, B: Extraction drift, C: Modified Pillar 
In the production drift (Figure 6A), 8 query points were analyzed. The SF remained constant until $1 \mathrm{~m}$ from the floor, but between $1 \mathrm{~m}$ and $2.5 \mathrm{~m}$ the SF was notably decreased in the TL and MTL (layouts). This is related to the relaxation zone $(\sigma 3<0)$. As shown in Figure $6 \mathrm{~B}$, the extraction drifts have SF results similar to the production drifts. Here, the SF starts to decrease at a height of $0.5 \mathrm{~m}$ in TL and MTL and at a height of $1 \mathrm{~m}$ in MSL. In general, all the layouts have worse results in terms of SF in the extraction drifts as compared with the production drifts. In the modified pillar (Figure 6C), the SF results show similar behavior in both layouts (MTL and MSL). The SF decreases in the middle of the walls due to stress relaxation.

\subsubsection{Roofs}

In the roofs, 5 query points were used between 3.3 and $3.9 \mathrm{~m}$ of height. Figure 7 shows the result for the three zones of interest indicated in the methodology (Production drift, extraction drift and modified pillar). The green line indicated in the bottom right of the graphs shows the query-point locations in the drift in a profile view.

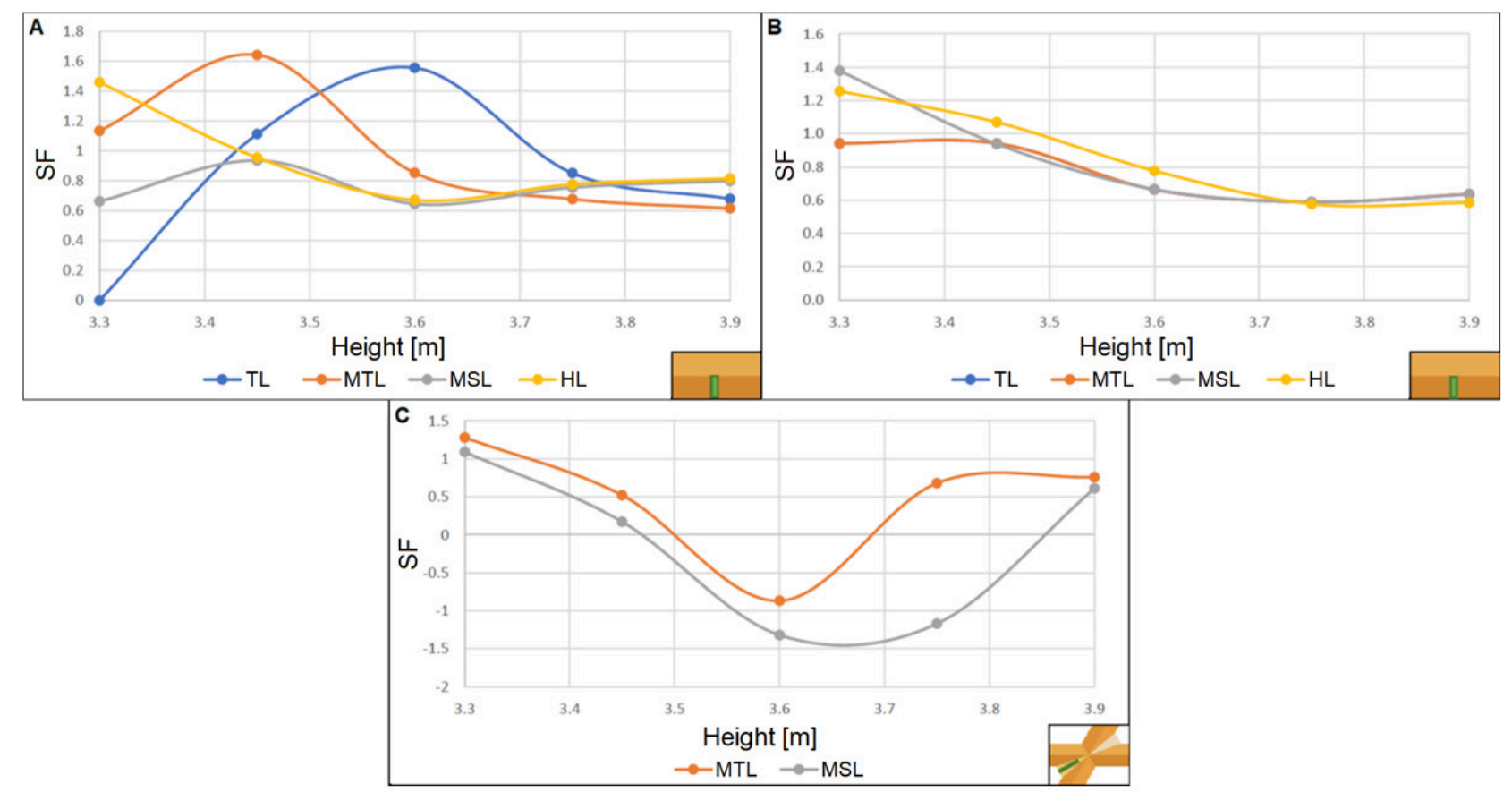

Figure 7 Strength factor results on drift's roofs, A: Production drift, B: Extraction drift, C: Modified Pillar

In the production drifts (Figure 7A), the SF is low at the beginning of the roof in the TL and MSL layouts. In the TL layout, the SF reaches almost 1.6 at $3.6 \mathrm{~m}$. At the top of the roof $(3.9 \mathrm{~m})$, the SF is around 0.7 in all layouts. The MTL layout has the best average results in the production drift. In the extraction drifts (Figure 7B), the SF is similar for all the layouts, decreasing for higher heights. The HL and MSL layouts have the best average results in the extraction drift. In the enlargement zones (Figure 7C), both layouts show similar FS results, which are slightly better for MTL. In both layouts, the SF is very low at $3.6 \mathrm{~m}$ of height due to stress relaxation.

\subsection{Major Principal stress}

The major principal stress $(\sigma 1)$ was measured in all the layouts considering the three areas of interest (production drift, extraction drift and modified pillars). Figures 8-10 show the $\sigma 1$ results for $\sigma 1>30$. The rock strength $\left(\sigma_{c i}\right)$ is $132 \mathrm{MPa}$. In general, the major principal stress simulated did not exceed the rock strength requirements. Furthermore, the major stress concentration was consistently observed in all layouts in the roof of the extraction drifts, production drifts and the modified pillars as can be seen in yellow, orange, and red. 


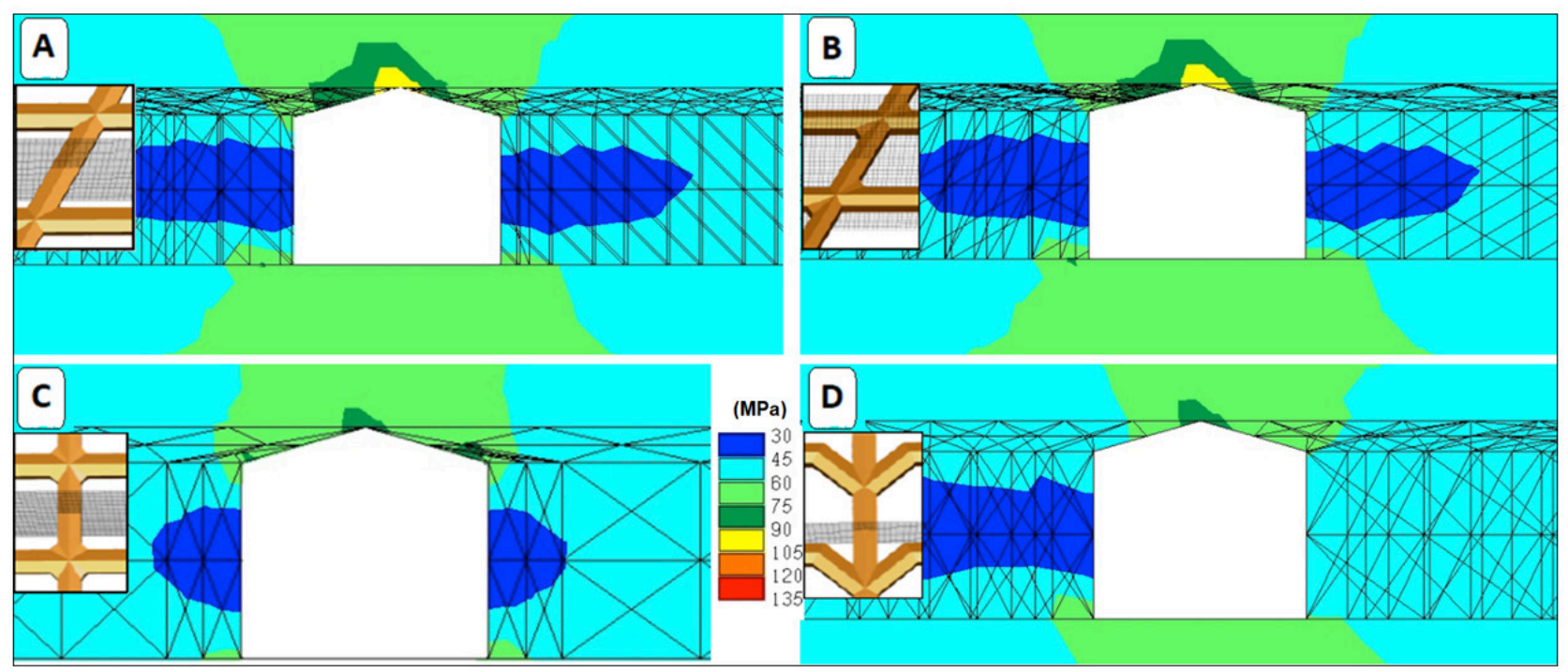

Figure $8 \sigma 1$ measured in production drifts. A: TL, B: MTL, C: MSL, D: HL

Figure 8 shows the results of the production drifts. Here, the highest $\sigma 1$ is observed in the roof of the TL and MTL layouts as seen in yellow. However, this stress is lower than $80 \%$ of $\sigma_{c i}$. The best distribution of $\sigma 1$ is reported in MSL and HL.
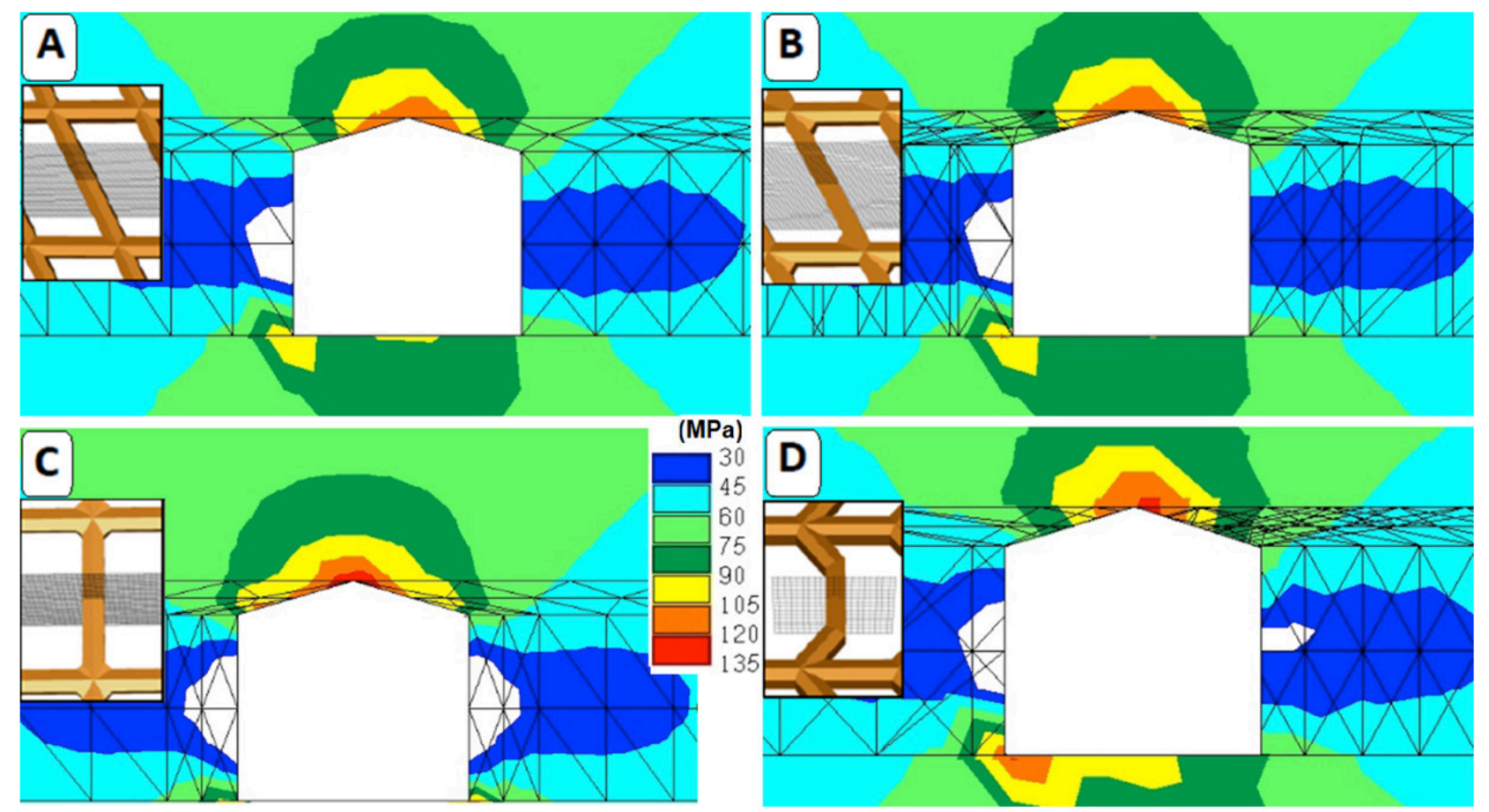

Figure $9 \sigma 1$ measured in extraction drifts. A: TL, B: MTL, C: MSL, D: HL

Figure 9 shows the results of the extraction drifts. The extraction drifts show the highest values of $\sigma 1$ in the roof and also in the floor corners of MSL and HL as can be observed in red; these stress concentrations locally exceed the rock strength in small areas of the roofs of these two layouts. 

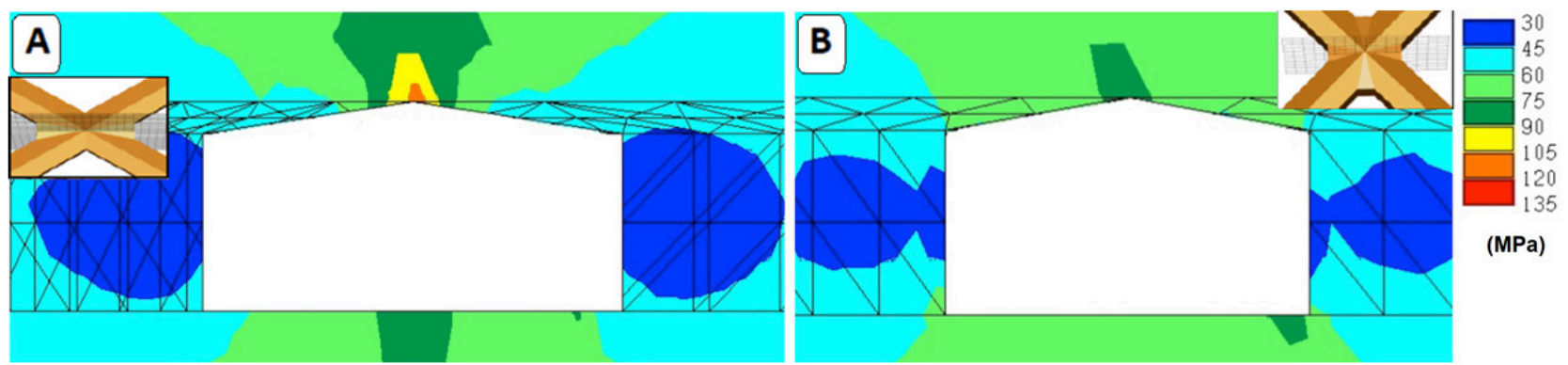

Figure $10 \sigma 1$ measured $(<0)$ in the modified pillars. A: MTL, B: MSL

Figure 10 shows the results of the modified pillars. Here, the highest $\sigma 1$ is observed in the roof of the MTL, however, this result does not exceed the required $\sigma_{c i}$. High stress concentrations were not observed in MSL. Then, in general, the $\sigma 1$ measurement shows acceptable stress concentrations around the excavations in the modified layouts.

\subsection{Minor principal stress}

Potential traction failures were identified in the three areas of interest (production drift, extraction drift and modified pillars; $\sigma 3<0 \mathrm{MPa}$ and $\sigma t i=-11 \mathrm{MPa}$ ). Figures $11-13$ show these areas and the $\sigma 3<0$. In the production drift (Figure 11), the $\sigma 3$ observed is over the tensile strength. The MSL presents the best safety condition in term of potential traction failure.

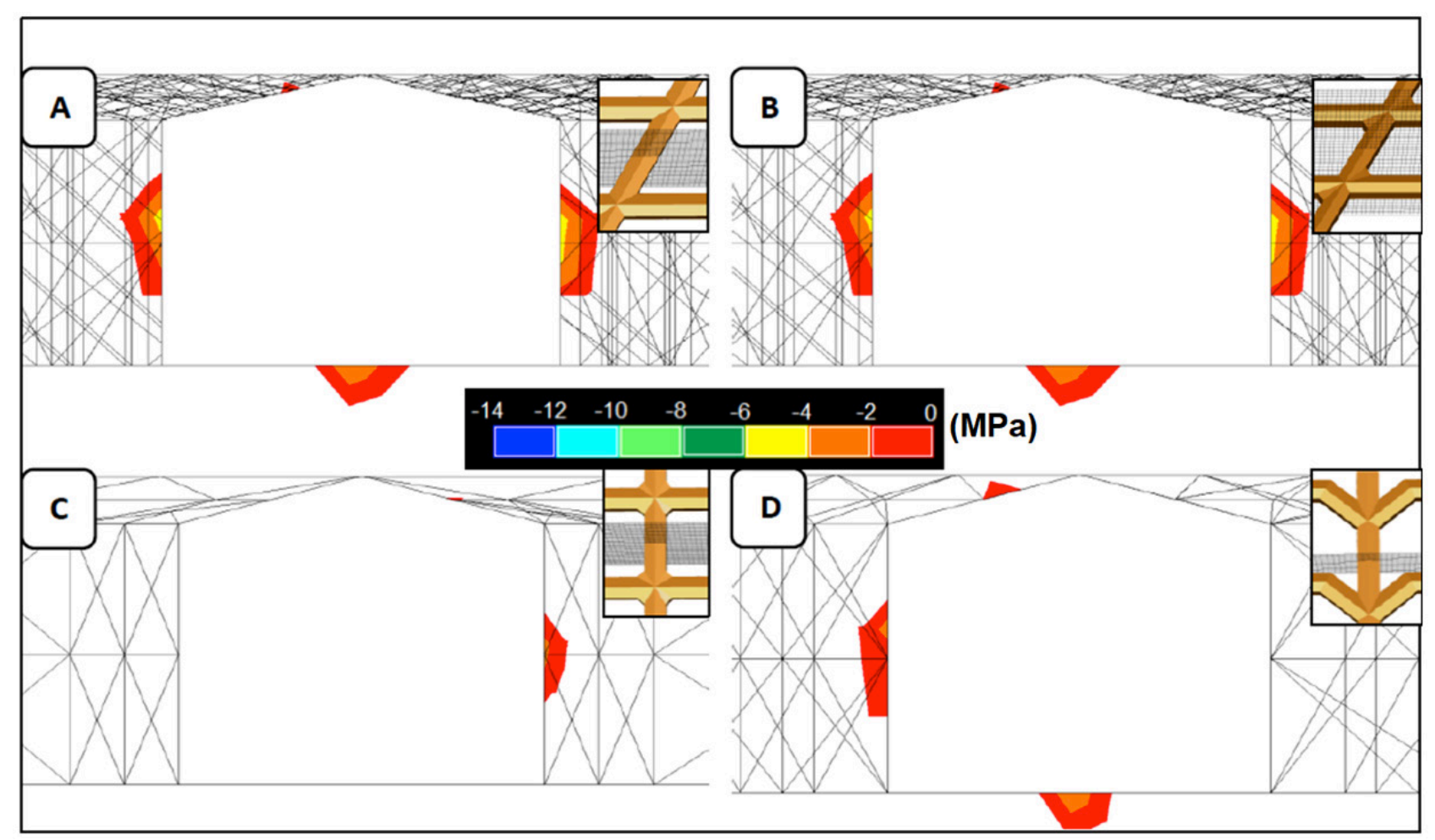

Figure $11 \sigma 3$ measured $(<0)$ in production drifts. A: TL, B: MTL, C: MSL, D: HL

The extraction-drift results are presented in Figure 12. Here, minor values of $\sigma 3$ are observed in the extraction-drift walls compared with the production drift as can be seen in yellow and green. In the roofs, no risk related to stress relaxation was observed. 


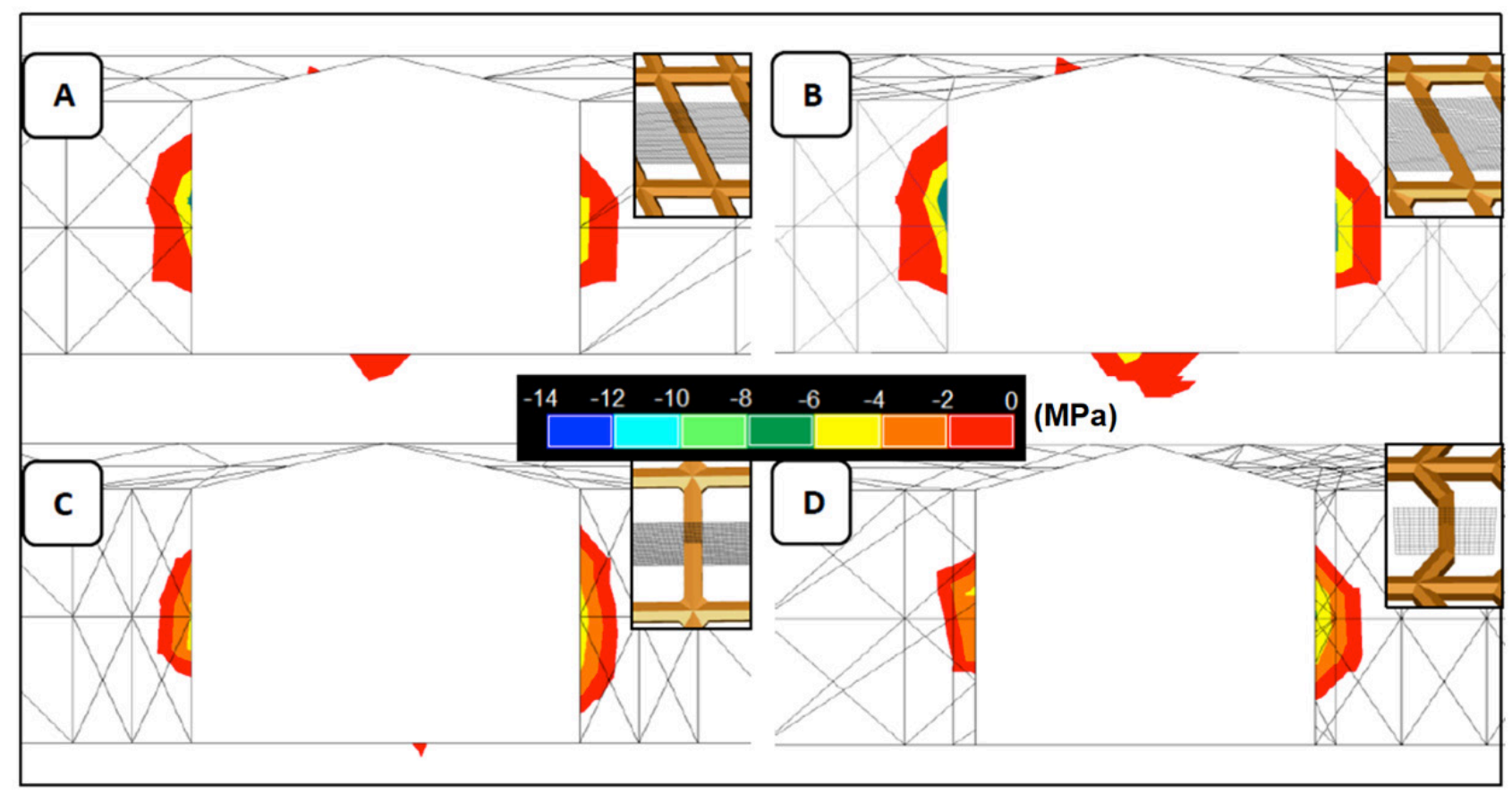

Figure $12 \sigma 3$ measured $(<0)$ in extraction drifts. A: TL, B: MTL, C: MSL, D: HL

Figure 13 shows the result for the modified pillars (MTL and MSL). MSL has lower $\sigma 3$ values than the MTL, particulary in the roof. In these modified zones, $\sigma 3<0$ is observed in the roofs. However, these magnitudes did not exceed the tensile strength of the rock.

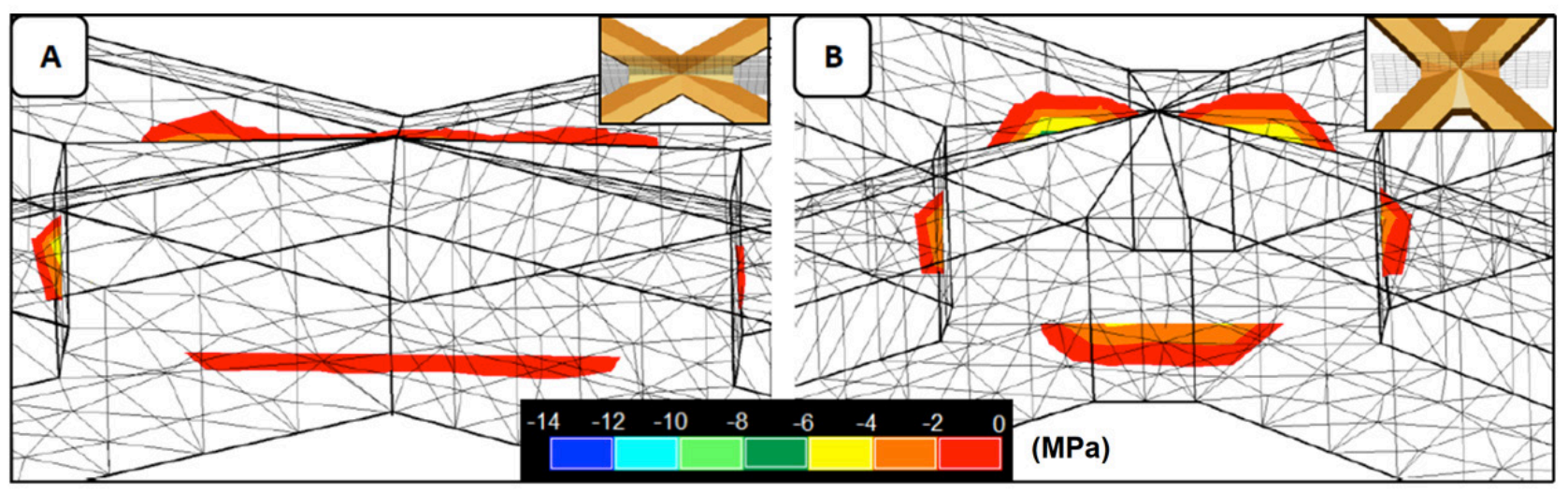

Figure $13 \sigma 3$ measured $(<0)$ in the modified pillars. A: MTL, B: MSL

\section{$4 \quad$ Productivity results}

The simulation model using the Arena softeware was initially calibrated using the base case El Teniente layout (TL), and from that case the MTL, MSL and HL layouts were subsequently simulated to compare productivity.

\subsection{Calibration stage}

First, the number of simulations required to ensure 95\% confidence $(\alpha=0.05)$ was 30. The base case (with the TL) was calibrated for both scenarios (the same and different probabilities of the LHD going to drawpoints). Table 3 shows the results of productivity and cycle time obtained in both scenarios using 4.8 hours of effective work per shift. Here, the real mine productivity is approximately 3,000 tpd. 
Table 3 Cycle time and productivity of the calibrated base case.

\begin{tabular}{|c|c|c|c|c|c|}
\hline LHD probability & Layout & \multicolumn{2}{|c|}{ Cycle time (min) } & \multicolumn{2}{c|}{ Productivity (tpd) } \\
\hline- & - & Min. & Max. & Min. & Max. \\
\hline Equal & El Teniente & 2.51 & 2.52 & 3017.1 & 3030.3 \\
\hline Different & El Teniente & 2.46 & 2.47 & 3019.4 & 3043.2 \\
\hline
\end{tabular}

The results show that the productivity of the simulation model are well calibrated to actual mine productivity. Then, the model was used to simulate the other layouts changing the LHD distances and restrictions to access drawpoints (depending on direction of movement in $\mathrm{TL}$ and $\mathrm{HL}$ ).

\subsection{Simulation results}

The productivity results are summarized in Figure 14 with all layouts and LHD probabilities (bucket capacity, loading time, dumping time, and velocity) shown. The layouts with pillar modifications, MTL and MSL, showed an increase in productivity of 35\% and 33\% respectively, compared with the base case (TL). In the HL layout, the productivity result was similar to the base case.

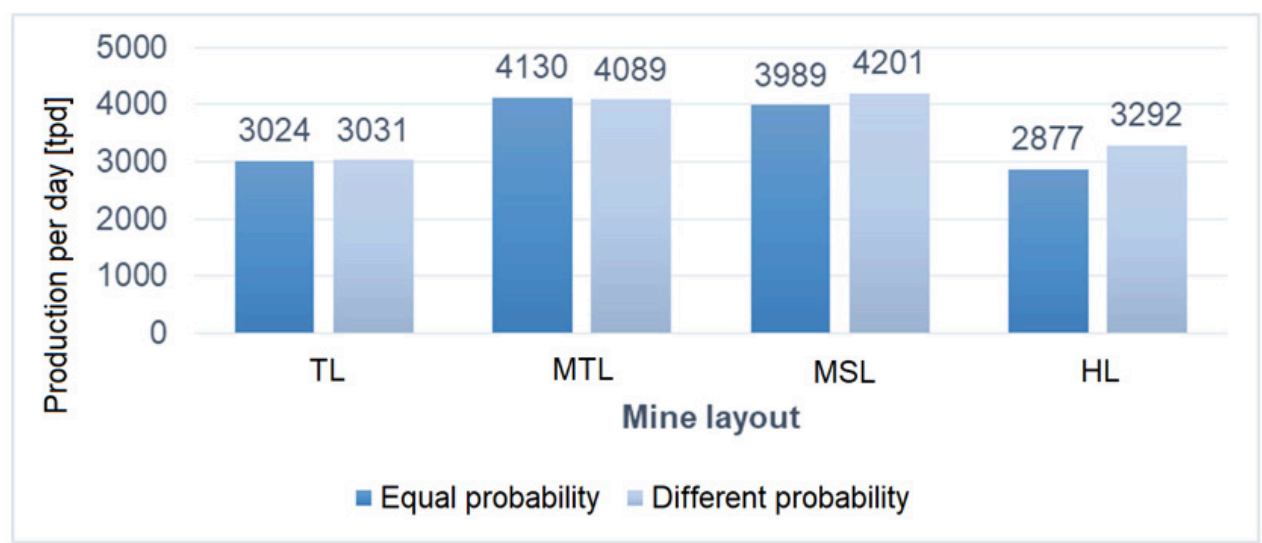

Figure 14 Extracted ore per day in simulated layouts

Results showed that there was not an important impact on productivity when there was a higher probability of the LHD going first to the drawpoint closest to the ore pass. This may be related to the probability that drawpoints closest to the ore pass are those that will also show hangups first and those hangups will require secondary reduction activities.

On other hand, Figure 15 summarizes the cycle-time results for the different layouts and probabilities. These results are directly related to the results of productivity, demonstrating that lower cycle times imply higher productivity. Cycle time decreased by $23 \%$ and $21 \%$ for MTL and MSL respectively, compared with the base case.

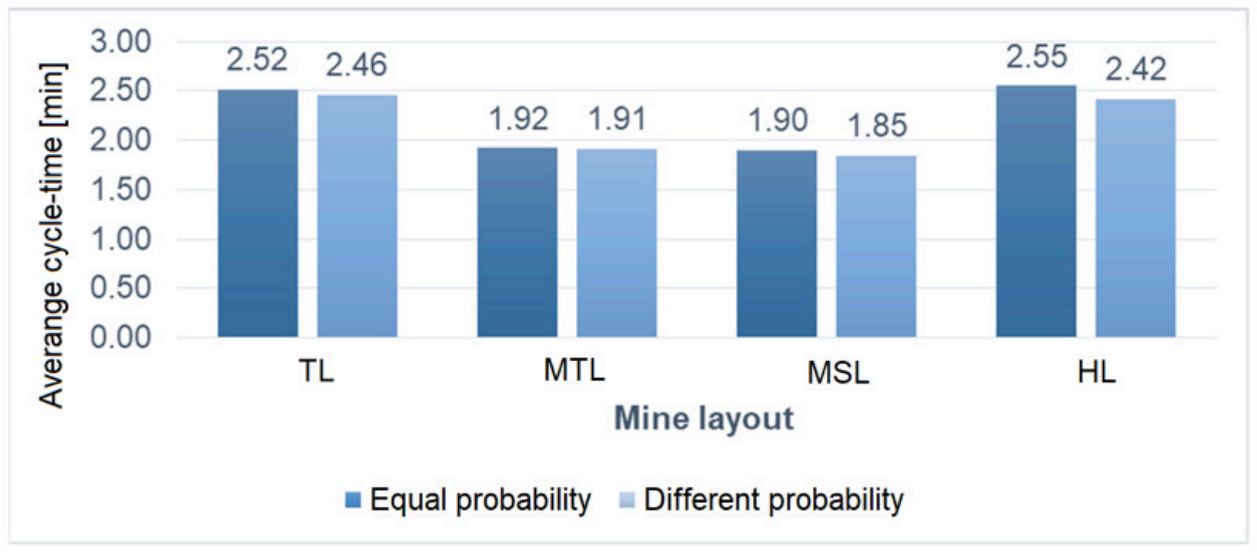

Figure 15 Time cycle in layouts simulated 
The simulation results, as expected, showed better productivity results when modified pillars are used in the layouts (MTL and MSL) because the LHD was required to travel less distance to go to all the drawpoints of a production drift, thus decreasing cycle time.

\section{Conclusions}

This work presented two variations of block caving layouts of the production level; these variations modified the pillars between the production and extraction drifts in an effort to increase LHD productivity. These modified layouts (MTL and MSL) were analyzed in term of two variables: stress distribution around the excavation and productivity. By comparing these modified layouts with common block caving layouts such as the El Teniente (TL) and Herringbone ( $\mathrm{HL}$ ) layouts, improvements could be observed in productivity, whereas the principal stress behavior did not show any significant differences.

Specific differences in stress were observed in some zones of the drift walls and roofs. In particular, the HL showed the best stability results in drift walls. While the MTL and HL obtained the best stability results in the drift and modified pillar roofs. On the other hand, the LHD productivity of the proposed layouts with modified pillars (MTL and MSL) increased more than 30\% when compared with a simulation of a base case production drift. These improvements are expected because the LHD cycle time decreases when the LHD can access drawpoints independently of the direction of movement due to the enlarged space for manuevering. Although no problems with stability related to the modified pillars were identified in this study, further analysis of abutment stress and rock deformation are required. Positive results, however, do suggest this type of modification would be useful and should be considered when designing mine layouts to increase LHD productivity.

\section{Acknowledgement}

The authors thank Gabriela Bravo for his help and comments on this work. R. Gómez wishes to thank CONICYT PFCHA/DOCTORADO BECAS CHILE/2019 - 72180000.

\section{References}

Aimin, Z \& Yongxue, S 2000, 'Application of block caving system in the Tongkuangyu Copper Mine', in G Chitombo (ed.), Proceedings of MassMin 2000, Australian Institute of Mining and Metallurgy, Melbourne, Australia, pp. 325-334.

Aguayo, A, Campos, C, Mansilla, M, Sougarret, J \& Susaeta, A 2004, 'LHD versus mechanized grizzly in III Panel of Andina', Proceedings of MassMin 2004, Santiago, Chil, pp. 415-520.

Arce, JC 2002, 'Drawpoint spacing, production and undercut level design for panel caving mehtod ini primary rock', El teniente, Bachelor Degree, Universidad de Santiago de Chile, Santiago, in Spanish.

Brzovic, A \& Villaescusa, E 2007, 'Rock mass characterization and assessment of block-forming geological discontinuities during caving of primary copper ore at the El Teniente mine, Chile', Int J Rock Mech Min Sc, vol. 44, no. 4, pp. 565-583.

Bull, G, Macsporran, G \& Baird, C 2004, 'The alternate design considered for the Argyle underground mine', in A Karzulovic \& M Alfaro (eds), Proceedings of Massmin 2004, Santiago, pp. 616-622.

Catalan, A, Dunstan, G, Morgan, M, Green, S, Jorquera, M \& Thornhill, T 2012, 'An "intensive" preconditioning methodology developed for the Cadia East panel cave project, NSW, Australia', Proceedings of MassMin 2012, Canadian Institute of Mining, Metallurgy and Petroleum, Westmount.

Capes, G, Sharrock, G \& Lowther, R 2012, 'Methodology for Understanding Drive Deformation and Damage in Variable Rock Types in a High Stress, Advanced Undercut', Proceedings of MassMin 2012, Canadian Institute of Mining, Metallurgy and Petroleum, Westmount.

Chacon, J, Gopfert, H \& Ovalle, A 2004, 'Thirty years evolution of block caving in Chile', Proceedings of Massmin 2004, A Karzulovic \& M Alfaro (eds), Santiago, pp. 387-92.

Chacón, J 1976, 'Block Caving and LHD - Extraction layouts thought', Revista Minerales, vol. 134, in Spanish.

Chitombo, DG 2010. 'Caving mining - 16 years after Laubscher's 1994 paper: Cave mining - state of the art', in Second 
International Symposium on Block and Sublevel Caving, ed. Y Potvin, Perth, pp. 45-62.

Codelco 2016, 'T14 E200: mining of Reservas Norte, El Teniente'. (Pre-feasibility study, Internal report), in Spanish.

Flores, G, Karzulovic, A \& Brown, ET 2004, 'Current practices and trends in cave mining', in A Karzulovic \& M Alfaro (eds), Proceedings of Massmin 2004, Santiago, pp. 83-90.

Hannweg, L, Lorig, L, van Hourt, G \& Guest, A 2004, 'Koffiefontein mine front cave - Case History', in A Karzulovic \& M Alfaro (eds), Proceedings of Massmin 2004, Santiago, pp. 225-30.

Hersant, D 2004, 'Mine design of the Argyle underground project', in A Karzulovic \& M Alfaro (eds), Proceedings of Massmin 2004, Santiago, pp. 610-615.

Hurtado, JP, Pereira J \& Campos R 2007, 'Final report - Fragmentation Backanalysis: Diablo Regimiento mine, Reno mine and Teniente 4 Sur Tonalita mine. (Pre-feasibility study, Internal report), in Spanish.

Jofre, J, Yáñez, P \& Ferguson, G 2000, 'Evolution in Panel Caving Undercutting and Drawbell Excavation, El Teniente Mine', in G Chitombo (ed.), Proceedings of MassMin 2000, Australian Institute of Mining and Metallurgy, Melbourne, Australia, pp. 249-260.

Laubscher, DH 2000, 'Horizontal LHD layouts', in Block cave manual, Julius Kruttschnitt Mineral Research Centre, Brisbane.

Rech, W 2001, 'Henderson mine', in Underground Mining Methods, ed/s. W. Hustrulid, R. Bullock, pp. 397-453.

Rocscience 1994, 'User Manual Examine 3D'.

Ross, I 2008, 'Northparkes E26 Lift 2 block cave - A case study', in 5th International Conference \& Exhibition on Mass Mining, Lulea, pp. 25-34.

Sepúlveda, DN 2017, 'Geological fault characterization based on critical variables and shear strength estimations, El Teniente mine', PhD Thesis, University of Concepción, Chile, in Spanish.

Wellmann, F 2001, 'Extraction layout selection: Isla LHD Project, Report PL-I-158/2001', in Spanish.

Yuming, L \& Jinfeng, Z 2008, 'Tongkuangyu mine's phase 2 project', in 5th International Conference \& Exhibition on Mass Mining, Lulea, pp. 53-61. 